\title{
ELECTROPHYSIOLOGICAL CHARACTERISTICS OF ISCHEMIC CARDIAC CELLS IN HYPOXIC AND HYPERKALEMIC CONDITIONS
}

\author{
Yutaka Horio, M.D., Ken OKumura, M.D., Katsuhide Nishi, M.D* \\ AND HaRUHIKo TOKUOMI, M.D.
}

\begin{abstract}
The difference in the electrophysiological properties between the subepicardial cells and the subendocardial cells (Purkinje fibers and ordinary myocardial cells) was examined in dogs using a microelectrode technique. The preparations were obtained one hour after coronary occlusion. Immediately after exposure to a hypoxic solution, spontaneous activities could be recorded in neither the subepicardial nor the subendocardial cells. The electrical activities induced by electrical stimulation disappeared 5-10 min after exposure to the hypoxic solution in the subepicardial cells, while they remained in the subendocardial cells. Vmax, action potential amplitude, action potential duration and resting membrane potential of the subendocardial cells were all reduced significantly in the hypoxic solution containing $7 \mathrm{mK} \mathrm{K}{ }^{+}$in contrast to those in the hypoxic solution containing $4 \mathrm{mM} \mathrm{K}^{+}(\mathrm{p}<0.001)$. In the hypoxic solution containing $15 \mathrm{mM} \mathrm{K}$, all cardiac cells depolarized partially and became electrically quiescent in both normal and ischemic cardiac cells. These findings support the idea that during regional hypoxia and hyperkalemia resulting from acute coronary occlusion, heterogeneous changes in electrical activities occur between the subepicardium and the subendocardium in the ischemic regions.
\end{abstract}

$\mathbf{T}$

HE pathogenesis of ventricular arrhythmias in acute coronary occlusion has been studied extensively using a bipolar-electrode technique in situ,,$^{-4}$ and a microelectrode technique in vitro..$^{5-8}$ Previous authors have indicated that there probably occur heterogeneous changes in electrical activity in the ischemic regions after coronary occlusion, and that ventricular arrhythmias in its early phase might be caused by a reentry mechanism due to the con-

Key Words:

Electrophysiology

Ischemic cardiac cells

Hypoxia and hyperkalemia

Ventricular arrhythmia duction delay in the ischemic myocardium. 1,3,4, 9-12 Microelectrode studies on the ischemic myocardium in situ have clarified one aspect of the electrophysiological properties of the subepicardial cells of the ischemic region ${ }^{13-15}$ and those in vitro have shown that the subendocardial Purkinje fibers and the ordinary myocardial cells survive even after an extensive myocardial infarction produced by coronary occlusion $5-8,16$ However, results obtained in vitro studies do not reflect the true changes in the electrical activities of the ischemic myocardium in situ, since most of the electrophysiological studies have been performed on preparations under superfusion with a well-oxygenated solution after

(Received September 10, 1981; accepted April 1, 1982)

First Department of Internal Medicine and ${ }^{*}$ Department of Pharmacology, Kumamoto University Medical School, Kumamoto, Japan

Address for correspondence: Yutaka Horio, M.D., First Department of Internal Medicine, Kumamoto University Medical School, 1-1-1, Honjo, Kumamoto 860, Japan 
coronary occlusion. It is known that ischemic or infarcted cardiac cells are exposed to an abnormal environment, including hypoxia, 17,18 hyperkalemia, ${ }^{19-23}$ acidosis ${ }^{24}$ deficiency of nutrients, ${ }^{18}$ catecholamine release, 23 and others $8,18,25-27$ Therefore, in order to elucidate the underlying mechanisms responsible for the initiation of ventricular arrhythmias in acute coronary occlusion, the electrophysiological properties of the ischemic cardiac cells should be examined under the conditions of a similar extracellular environment to that in coronary occlusion.

The present experiments were designed to clarify the electrophysiological properties of the subepicardial cells, the subendocardial Purkinje fibers and the ordinary myocardial cells under superfusion with hypoxic and hyperkalemic Tyrode's solution one hour after coronary occlusion.

\section{METHODS}

\section{Experimental Preparations}

Twenty-nine adult mongrel dogs $(10-15 \mathrm{~kg})$ were anesthetized with sodium pentobarbital (30 $\mathrm{mg} / \mathrm{kg}$, iv) and ventilated artificially by a positive pressure respirator (Respirator Model B2, IgarashiIka Kogyo). The $\mathrm{PO}_{2}$ of arterial blood was maintained at $90-100 \mathrm{mmHg}$ by adding oxygen. The chest was opened at the left fourth intercostal space, and the heart was cradled in the pericardium. The anterior descending coronary artery was isolated from the great cardiac vein $10-20 \mathrm{~mm}$ distal to its origin, and ligated according to the two-stage ligation method of Harris ${ }^{28}$ One hour after coronary occlusion, the heart was removed rapidly, put in Tyrode's solution at $4^{\circ} \mathrm{C}$, and tissue samples for electrophysiological examinations were obtained. An infarcted epicardial preparation of $2 \mathrm{~cm} \times 3 \mathrm{~cm}$ in area and 3-4 $\mathrm{mm}$ in thickness (Fig. 1) was dissected from the region showing the most marked cyanosis with an abnormal epicardial movement. An infarcted endocardial preparation of the same size as the epicardial one was obtained from the most pale-colored region in the anterior papillary muscle. Normal preparations were dissected from the epicardial and the endocardial layers of normal dogs in the same manner as in the infarcted ones. For simultaneous electrophysiological studies of both the subepicardial and the subendocardial cells under identical conditions, these preparations were pinned with the epicardial and endocardial surface

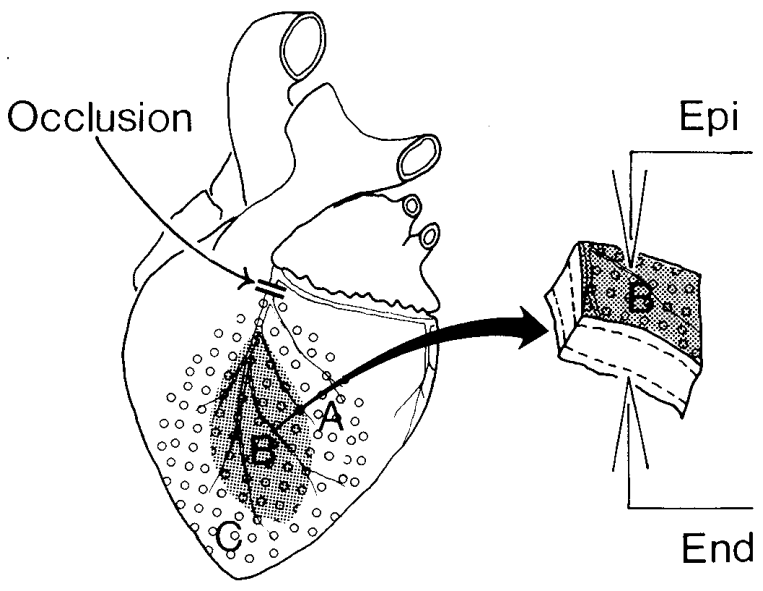

Fig.1. Diagramatic representation of experimental procedures. One hour after coronary occlusion, 13 dogs survived. Five to 15 min after coronary occlusion, 3 dogs died from ventricular fibrillation. The infarcted or ischemic region ( $A, B$ and $C$ ) appeared cyanotic and moved abnormally. The most cyanotic area (shaded, B) of the epicardial layer was excised as an epicardial preparation and the most pale colored area of the endocardial layer was excised as an endocardial preparation.

upwards-away from the base of a $50 \mathrm{ml}$ superfusion chamber. The preparations were superfused at a rate of $20 \mathrm{ml} / \mathrm{min}$ with Tyrode's solution equilibrated with a gas mixture of $95 \% \mathrm{~N}_{2}+5 \%$ $\mathrm{CO}_{2}$. Tyrode's solution containing $4 \mathrm{mM} \mathrm{K}^{+}$was composed of the following components (mM): $\mathrm{NaCl} 137, \mathrm{NaHCO}_{3} 18$, glucose 5.5, $\mathrm{NaH}_{2} \mathrm{PO}_{4}$ $1.8, \mathrm{MgCl}_{2} \quad 0.5, \mathrm{CaCl}_{2} 2.8$ and $\mathrm{KCl} 4.0$. In order to change the potassium ion content of Tyrode's solution, the equimolar sodium content was reduced. Temperature was maintained at $36.5 \pm$ $0.5^{\circ} \mathrm{C}$. The $\mathrm{PO}_{2}$ of Tyrode's solution equilibrated with a gas mixture of $95 \% \mathrm{~N}_{2}+5 \% \mathrm{CO}_{2}$ ranged from 35 to $50 \mathrm{mmHg}$, and the $\mathrm{pH}$ from 7.3 to 7.4. The well-oxygenated solution was equilibrated with a gas mixture of $95 \% \mathrm{O}_{2}+5 \%$ $\mathrm{CO}_{2}$ to obtain a $\mathrm{PO}_{2}$ of $450-550 \mathrm{mmHg}$. To measure $\mathrm{PO}_{2}$ and $\mathrm{pH}, 1-2 \mathrm{ml}$ of Tyrode's solution at a level of one $\mathrm{mm}$ above the tissue was sampled and analyzed periodically using a $\mathrm{pH} /$ blood gas analyzer (Model Micro 13, Instrumental Laboratory Inc.).

\section{Experimental Protocols}

Group A (control group): Five normal preparations were superfused with the well-oxygenated Tyrode's solution containing $4 \mathrm{mM} \mathrm{K} \mathrm{K}^{+}$immedi- 
TABLE I ACTION POTENTIAL CHARACTERISTICS OF NORMAL CARDIAC CELLS UNDER A WELL-OXYGENATED CONDITION

\begin{tabular}{ccccccc}
\hline \hline Cells & $n$ & $\begin{array}{c}\text { RMP } \\
(\mathrm{mV})\end{array}$ & $\begin{array}{c}A P A \\
(\mathrm{mV})\end{array}$ & $\begin{array}{c}50 \% \text { APD } \\
(\mathrm{msec})\end{array}$ & $\begin{array}{c}\text { 80\% } \\
(\mathrm{msec})\end{array}$ \\
\hline Epi-m & 68 & $80.2 \pm 6.6$ & $97.4 \pm 6.3$ & $151.5 \pm 24.6$ & $179.2 \pm 24.8$ & $93.9 \pm 24.9$ \\
End-P & 30 & $78.6 \pm 6.1$ & $110.0 \pm 8.4$ & $203.3 \pm 30.9$ & $256.0 \pm 30.9$ & $319.8 \pm 64.9$ \\
End-m & 65 & $82.2 \pm 6.6$ & $105.2 \pm 7.2$ & $177.0 \pm 26.3$ & $210.0 \pm 30.0$ & $134.0 \pm 35.8$ \\
\hline
\end{tabular}

Each value represents the mean $\pm S D$ of the cardiac action potential characteristics obtained from 5 normal preparations 60-70 min after superfusion. $n=n u m b e r$ of cells, Epi-m $=$ subepicardial cell, End-P = subendocardial Purkinje fiber, End- $m=$ subendocardial ordinary myocardial cell, RMP = resting membrane potential, $A P A=$ action potential amplitude, $50 \%$ and $80 \%$ APD $=$ action potential duration at $50 \%$ and $80 \%$ repolarization, respectively.

ately after excision from the heart. During a 60-min period of superfusion, transmembrane potentials were recorded from the subepicardial cells, the subendocardial Purkinje fibers and the ordinary myocardial cells.

Group B (well-oxygenated group): Three infarcted preparations were superfused with the well-oxygenated Tyrode's solution containing 4 $\mathrm{mM} \mathrm{K}$ immediately after excision from the heart. Recordings of transmembrane potentials were begun immediately after superfusion.

Group C (hypoxic group): In the hypoxic Tyrode's solution containing $4 \mathrm{mM} \mathrm{K}$, electrophysiological properties of 5 infarcted and 5 normal preparations were examined immediately after excision from the heart. Recordings of transmembrane potentials were begun immediately after superfusion with the hypoxic Tyrode's solution.

Group D (hypoxic and hyperkalemic group): Five infarcted and 3 normal preparations were initially superfused with the hypoxic Tyrode's solution containing $7 \mathrm{mM} \mathrm{K}^{+}$immediately after excision from the heart. Recordings of transmembrane potentials were begun immediately after superfusion. After 70-min superfusion with the hypoxic Tyrode's solution containing $7 \mathrm{mM}$ $\mathrm{K}^{+}$, the superfusate was replaced by the hypoxic Tyrode's solution containing $15 \mathrm{mM} \mathrm{K}^{+}$. Recording of transmembrane potentials were again done 5-10 min after superfusion with this solution.

\section{Recordings and Measurements}

For recording transmembrane potentials, the preparations were stimulated at a basic cycle length of $600 \mathrm{msec}$ through Teflon-coated bipolar silver wire electrodes placed on the surface of each preparation. Rectangular pulses of one msec in duration and with a voltage of twice the threshold level were applied through stimulating electrodes using a pulse generator (Cardiac Stimulator 3F51, San-Ei). Transmembrane potentials were recorded by conventional glass microelectrode technique. The glass microelectrode filled with $3 \mathrm{M} \mathrm{KCl}$ (tip resistance of 10-20 megohms) was coupled by platinum wire to a high input impedance amplifier with capacitance neutralization (MEZ-7101, Nihon Koden). A specially designed Vmax analyzer (ED-600G, Nihon Koden) was used to obtain the maximum rate of rise (Vmax) of phase zero of each action potential. Outputs of the amplifier and the Vmax analyzer were displayed on an oscilloscope (Tektronix 5112, Sony/Tektronix) and photographed by a camera (RLG-6101, Nihon Koden). Resting membrane potential, action potential amplitude, action potential duration at $50 \%$ and $80 \%$ repolarization $(50 \%$ APD and $80 \%$ APD, respectively) and Vmax were measured as parameters of each action potential characteristics. At each preparation, action potentials were recorded from the most superficial fiber to the 3 fibers beneath the surface of the epicardium and the endocardium by advancing the microelectrode downwards.

All data were represented as mean $\pm \mathrm{SD}$. To compare data obtained from different conditions, the modified $t$-test ${ }^{29}$ was used. A p-value of 0.05 or less was considered significant.

\section{RESULTS}

\section{Electrical Activity under a Well-oxygenated Con- dition}

Normal Preparations: Immediately after excision from the heart, preparations were 


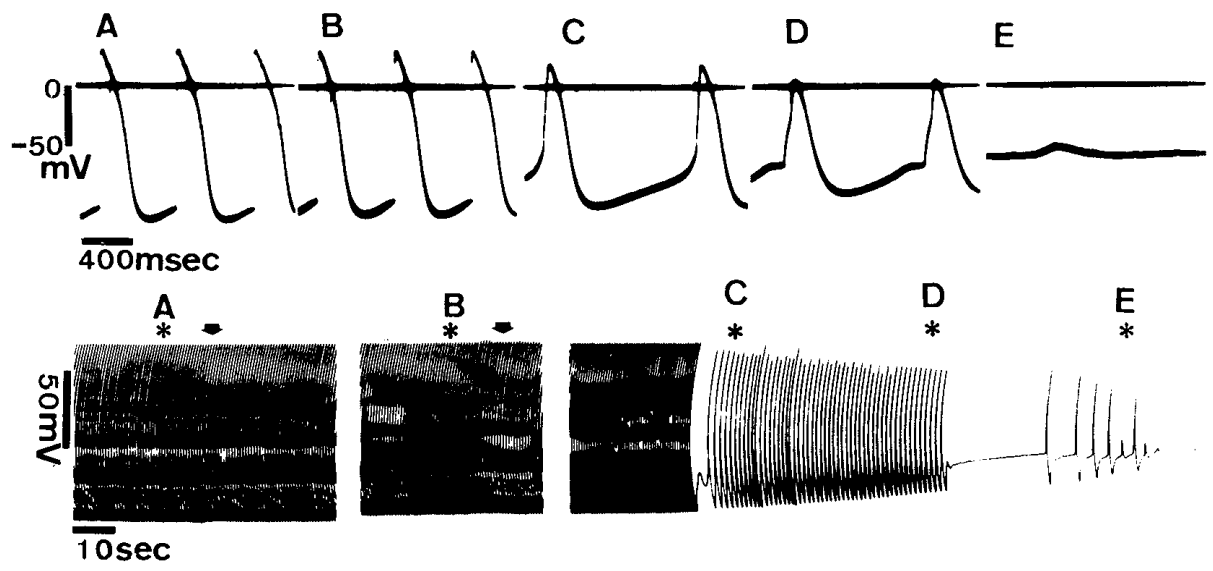

Fig.2. Effects of verapamil on spontaneous electrical activity of a subendocardial cell obtained from infarcted preparation in the well-oxygenated solution. The upper panel shows sample recordings of action potentials before the application of verapamil (A) and after (B, C, D and E). The lower panel shows continuous action potentials recorded with a pen-writing recorder. Asterisks indicate the points at which action potentials were taken. Verapamil at a concentration of $1 \times 10^{-6} \mathrm{~g} / \mathrm{ml}$ was applied at a point indicated by the arrow in $A$. Five $\min$ after $A$, an additional verapamil (a final concentration: $5 \times 10^{-6} \mathrm{~g} / \mathrm{ml}$ ) was applied at the arrow in $\mathrm{B}$. Recording was interrupted for one min between $\mathrm{B}$ and $\mathrm{C}$.

TABLE II ACTION POTENTIAL CHARACTERISTICS OF ISCHEMIC CARDIAC CELLS UNDER A WELL-OXYGENATED CONDITION

\begin{tabular}{ccccccc}
\hline \hline Cells & $n$ & $\begin{array}{c}\text { RMP } \\
(\mathrm{mV})\end{array}$ & $\begin{array}{c}A P A \\
(\mathrm{mV})\end{array}$ & $\begin{array}{c}50 \% \text { APD } \\
(\mathrm{msec})\end{array}$ & $\begin{array}{c}80 \% \text { APD } \\
(\mathrm{msec})\end{array}$ & $\begin{array}{c}\text { Vmax } \\
(\mathrm{V} / \mathrm{sec})\end{array}$ \\
\hline Epi-m & 33 & $77.4 \pm 11.1$ & $90.5 \pm 8.9$ & $168.3 \pm 23.4$ & $196.9 \pm 24.2^{*}$ & $81.1 \pm 19.4$ \\
End-P & 23 & $77.9 \pm 7.7$ & $109.3 \pm 12.5$ & $210.1 \pm 21.2$ & $265.2 \pm 29.5$ & $301.9 \pm 111.4$ \\
End-m & 21 & $80.1 \pm 6.9$ & $104.0 \pm 6.0$ & $212.5 \pm 29.7^{* *}$ & $254.7 \pm 28.8^{* *}$ & $130.4 \pm 36.0$ \\
\hline
\end{tabular}

Each value represents the mean $\pm S D$ of the cardiac action potential characteristics obtained from 3 infarcted preparations 60-70 min after superfusion. $*=p<0.005, * *=p<0.001$, as compared with the values in the normal preparations under a well-oxygenated condition shown in Table $I$.

exposed to the well-oxygenated solution containing $4 \mathrm{mM} \mathrm{K}^{+}$. In endocardial preparations, spontaneously occurring action potentials with a rate of $50-60 / \mathrm{min}$ were recorded, but disappeared within 15 min after the beginning of superfusion. Action potentials of the subendocardial Purkinje fibers were determined according to the criteria described by previous investigators ${ }^{30}$ In subepicardial preparations, spontaneously occurring action potentials were recorded immediately after superfusion either at a rate of less than 10/ min or not at all. They also disappeared within $5-10 \mathrm{~min}$ after the beginning of superfusion. The amplitude and the configuration of action potentials of the subepicardial cells, the subendocardial Purkinje fibers and the ordinary myocardial cells taken from normal preparations showed electrophysiological properties similar to those described by previous investigators $5,7,30,31$ Mean values of each parameter of action potentials recorded from normal preparations are summarized in Table I as the controls.

Infarcted Preparations: After excision of the preparations from the infarcted myocardial region, the specimen was immediately transferred into the well-oxygenated solution and the effects of reoxygenation on electrophysiological properties of the infarcted myocardial cells were examined. The subepicardial cells of the infarcted myocardium responded well to electrical stimulation. At the initial stage of reoxygenation (10 $20 \mathrm{~min}$ ), the resting membrane potential was low, ranging from $-50 \mathrm{mV}$ to $-72 \mathrm{mV}$, and the action potential amplitude was also significantly 


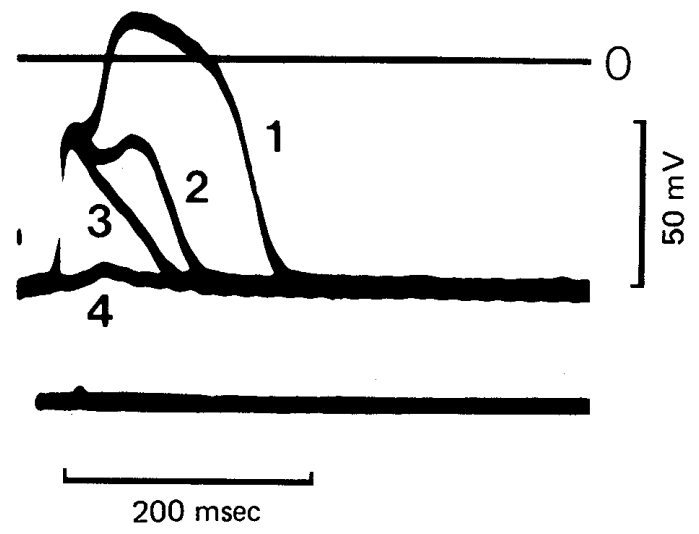

Fig.3. Superimposion of recording of action potentials of a subepicardial cell in a normal preparation $12 \mathrm{~min}$ after exposure to the hypoxic solution containing $4 \mathrm{mM}$ $\mathrm{K}^{+}$. The amplitudes of phase zero were markedly reduced and the action potentials $(1,2,3$ and 4 in the panel) deteriorated progressively. Finally the cell did not respond to electrical stimulation at 15 min under the hypoxic condition. In the panel, the top trace is the zero reference potential, the middle traces are the transmembrane potentials and the bottom traces are Vmax. Calibrations: transmembrane potential-the right vertical bar shows $50 \mathrm{mV}$; time marks-the lower horizontal bar shows $200 \mathrm{msec}$.

low as compared with those of the normal preparations. However, when the preparations were reoxygenated for a longer period (30-60 $\mathrm{min}$ ), the action potential duration was prolonged, and in some cells phase 2 of repolarization of action potential persisted for longer than $150 \mathrm{msec}$. At the end of the prolonged reoxygenation (measured for 10 min after a 60-min period of reoxygenation) the resting membrane potential, action potential amplitude and Vmax of the subepicardial cells did not increase significantly (Table II).

In contrast to the subepicardial cells, the subendocardial Purkinje fibers and the ordinary myocardial cells showed a variety of electrical activities in the well-oxygenated solution. In the early stage of reoxygenation, the spontaneously occurring action potentials with apparent slow diastolic depolarization similar to the phase 4 of the pacemaker potential in the sinoatrial node were frequently recorded. Figure 2 shows action potentials recorded from infarcted preparations at $30 \mathrm{~min}$ of reoxygenation. Spontaneously occurring action potentials were completely abolished by application of verapamil at a con-

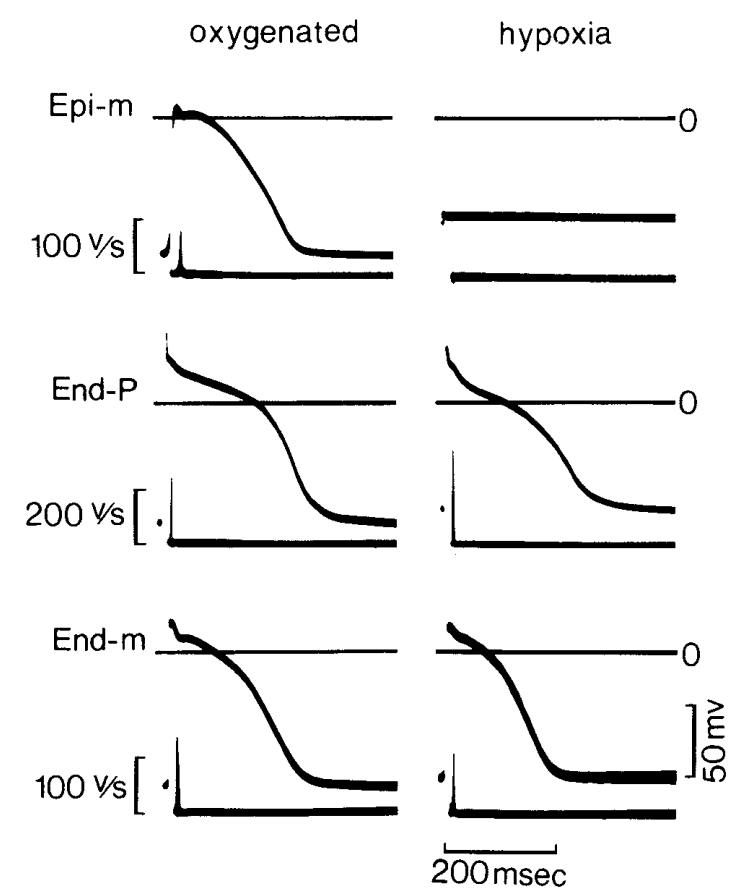

Fig.4. Effects of hypoxia on a subepicardial cell, a subendocardial Purkinje fiber and an ordinary myocardial cell in normal preparation. The format in each panel is the same as in Fig. 3. The left panels are control recordings $60 \mathrm{~min}$ after superfusion with the well-oxygenated solution containing 4 $\mathrm{mM} \mathrm{K}^{+}$; and the right panels are recordings taken $60 \mathrm{~min}$ after exposure to the hypoxic solution containing $4 \mathrm{mM} \mathrm{K}$. Epi- $\mathrm{m}=$ subepicardial cell, End-P = subendocardial Purkinje fiber, End-m = subendocardial ordinary myocardial cell (see text for details). Calibrations: transmembrane potential-the right vertical bar shows 50 $\mathrm{mV} ; \mathrm{Vmax}$ - the left vertical bars show 100 $\mathrm{V} / \mathrm{sec}$ (in the upper and lower panels) and $200 \mathrm{~V} / \mathrm{sec}$ (in the middle panels); time marks-the lower horizontal bar shows $200 \mathrm{msec}$

centration of $1 \times 10^{-6} \mathrm{~g} / \mathrm{ml}$. In other instances, action potentials with a short duration occurred at a relatively low firing rate $(6-10$ beats $/ \mathrm{min})$. When the preparations were superfused with the well-oxygenated solution for $30-60 \mathrm{~min}$, the spontaneous electrical activities became less prominent, but were still recordable from some of the cells. The resting membrane potential and action potential duration of the subendocardial Purkinje fibers and the ordinary myocardial cells tended to increase with the time of exposure to the well-oxygenated solution, but the action potential characteristics of the subendocardial Purkinje fibers of infarcted preparations did not. 
TABLE III EFFECTS OF HYPOXIA ON ACTION POTENTIAL CHARACTERISTICS OF ISCHEMIC AND NORMAL CARDIAC CELLS

\begin{tabular}{|c|c|c|c|c|c|c|c|}
\hline $\begin{array}{l}\text { Time } \\
\text { (min) }\end{array}$ & $\begin{array}{l}\text { Prepa- } \\
\text { ration }\end{array}$ & $n$ & $\begin{array}{l}R M P \\
(m V)\end{array}$ & $\begin{array}{l}A P A \\
(m V)\end{array}$ & $\begin{array}{c}50 \% \text { APD } \\
\text { (msec) }\end{array}$ & $\begin{array}{c}80 \% \text { APD } \\
\text { (msec) }\end{array}$ & $\begin{array}{c}V \max \\
(V / \text { sec })\end{array}$ \\
\hline \multicolumn{8}{|c|}{ Epi-m } \\
\hline \multirow{3}{*}{$10-20$} & $N$ & 44 & 60.6 & 68.0 & 105.8 & 123.1 & 31.6 \\
\hline & $N$ & 44 & $\pm 4.2 * * *$ & $\pm 4.4(20)^{* * *}$ & $\pm 46.8(20)^{* * *}$ & $\pm 48.0(20)^{* * *}$ & $\pm 20.5(20)^{* * *}$ \\
\hline & $I$ & 47 & $\begin{array}{r}64.2 * * * \\
\pm \quad 6.4 \S \S \S\end{array}$ & $N D$ & $N D$ & $N D$ & $N D$ \\
\hline \multirow[t]{2}{*}{$60-70$} & $N$ & 47 & $\begin{array}{r}66.0^{* * *} \\
\pm 4.3^{t+t}\end{array}$ & $\begin{array}{l}77.6 \\
\pm 8.6(19)^{* * *}\end{array}$ & $\begin{array}{l}84.4 \\
\pm 13.0(19)^{* * *}\end{array}$ & $\begin{aligned} & 98.0 \\
\pm & 14.4(19)^{* * *}\end{aligned}$ & $\begin{aligned} & 69.0 \\
\pm & 34.5(19)^{* * *}\end{aligned}$ \\
\hline & $I$ & 53 & $\begin{array}{l}64.6 \\
\pm \quad 9.2 * * *\end{array}$ & $N D$ & $N D$ & $N D$ & $N D$ \\
\hline \multicolumn{8}{|c|}{ End-P } \\
\hline \multirow{4}{*}{$10-20$} & $N$ & 34 & 74.0 & 104.5 & 136.3 & 192.4 & 338.0 \\
\hline & & & $\pm 6.0^{* *}$ & $\pm 9.9^{*}$ & $\pm 28.8 * * *$ & $\pm 27.5 * * *$ & \pm 57.4 \\
\hline & $I$ & 31 & 74.1 & 106.5 & 132.2 & 185.9 & 267.4 \\
\hline & & 31 & \pm 7.4 & \pm 11.3 & \pm 48.4 & \pm 50.7 & $\pm 75.0 * \S \S$ \\
\hline \multirow[t]{2}{*}{$60-70$} & $N$ & 47 & $\begin{array}{l}78.1 \\
\pm 5.6 t+\end{array}$ & $\begin{array}{l}111.2 \\
\pm 5.1+t t\end{array}$ & $\begin{array}{l}166.4^{* * * *} \\
\pm 19.0^{t+t}\end{array}$ & $\begin{array}{l}220.3^{* * *} \\
\pm 23.6\end{array}$ & $\begin{array}{l}378.6 \\
\pm 56.0^{* * *}\end{array}$ \\
\hline & $I$ & 42 & $\begin{array}{r}75.9 \\
\pm \quad 7.4\end{array}$ & $\begin{array}{l}108.3 \\
\pm 10.4\end{array}$ & $\begin{array}{l}148.2 \text { *** } \\
\pm 34.6\end{array}$ & $\begin{array}{l}206.2 * * * \\
\pm 36.5 \%\end{array}$ & $\begin{array}{l}306.6 \\
\pm 90.2 \S \S \S\end{array}$ \\
\hline \multicolumn{8}{|c|}{ End-m } \\
\hline \multirow[t]{2}{*}{$10-20$} & $N$ & 31 & $\begin{array}{l}71.3 \\
\pm \quad 3.4^{* * *}\end{array}$ & $\begin{array}{l}94.2 \\
\pm \quad 4.5 * * *\end{array}$ & $\begin{array}{l}137.3 \\
\pm 30.1^{* * *}\end{array}$ & $\begin{array}{l}169.9 \\
\pm 34.4^{* * *}\end{array}$ & $\begin{array}{l}136.4 \\
\pm 39.3\end{array}$ \\
\hline & $I$ & 34 & $\begin{array}{l}67.1 \\
\pm \quad 8.4^{* * *}\end{array}$ & $\begin{array}{l}87.2 \\
\pm 13.4^{* * *}\end{array}$ & $\begin{array}{l}99.7 \\
\pm 42.9 * * *\end{array}$ & $\begin{array}{l}138.4 \\
\pm 51.6 * * *\end{array}$ & $\begin{array}{l}127.8 \\
\pm 77.7\end{array}$ \\
\hline \multirow[t]{2}{*}{$60-70$} & $N$ & 45 & $\begin{array}{r}74.0^{* * * *} \\
\pm 4 t+\end{array}$ & $\begin{array}{l}100.2^{* * * *} \\
\pm 6.9^{* t}\end{array}$ & $\begin{array}{l}128.4 \\
\pm 26.9 * * *\end{array}$ & $\begin{array}{l}169.2 \\
\pm 24.3 * * *\end{array}$ & $\begin{array}{l}134.8 \\
\pm 42.0\end{array}$ \\
\hline & $I$ & 38 & $\begin{array}{r}69.7^{* * * *} \\
\pm \quad 5.6\end{array}$ & $\begin{aligned} & 96.2^{* * *} \\
\pm & 11.1\end{aligned}$ & $\begin{array}{l}117.5^{* * * *} \\
\pm 30.8_{\dagger}^{\S \S}\end{array}$ & $\begin{array}{l}171.7^{* * * *} \\
\pm 36.9^{t t}\end{array}$ & $\begin{array}{l}133.6 \\
\pm 49.7\end{array}$ \\
\hline
\end{tabular}

Each value represents the mean $\pm S D$ of the cardiac action potential characteristics obtained from 5 normal preparations $(N)$ and 5 infarcted preparations $(I)$ 10-20 min and 60-70 min after exposure to the hypoxic solution. Numerals in parentheses indicate the number of cardiac cells which preserved electrical activities. ${ }^{*}=p<0.05,{ }^{*}=p<0.005, *^{* *}=p<0.001$; significance of the difference between controls (Table I) and normal or infarcted preparations under the hypoxic condition. $\S=p<0.05, \quad \S \S=p<0.005, \S \S \S=$ $p<0.001$ : significance of the difference between normal and infarcted preparations under the hypoxic condition. $t=p<0.05, t t=p<0.005, t+t=p<0.001$ : significance of the difference between initial stage of the hypoxic condition $(10-20 \mathrm{~min})$ and end stage $(60-70 \mathrm{~min})$. ND = no data due to a lack of response to electrical stimulation.

On the other hand, the action potential duration of the subendocardial ordinary myocardial cells of infarcted preparations was significantly prolonged as compared with those of normal prepa- rations (Table II).

Electrical Activity under a Hypoxic Condition Normal Preparations: Within 10-20 min 
$15 \min$
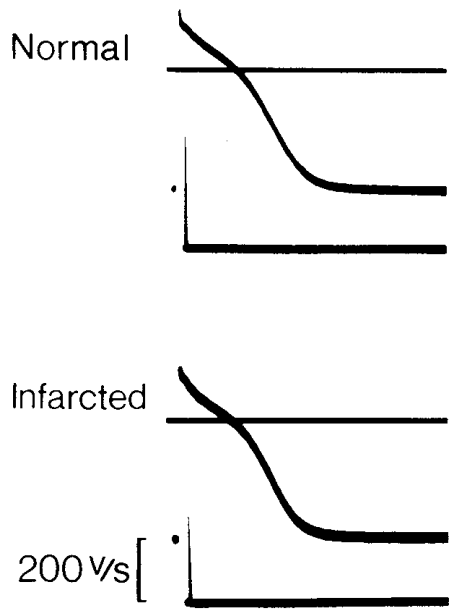

$30 \mathrm{~min}$
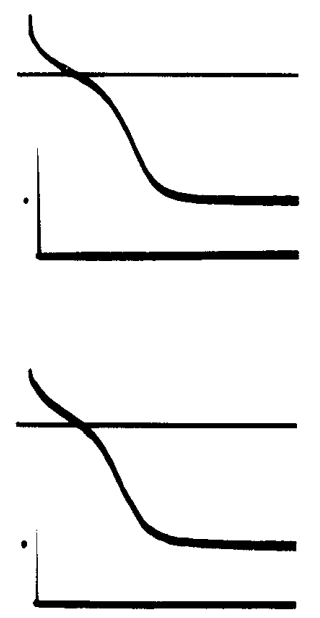

$60 \mathrm{~min}$
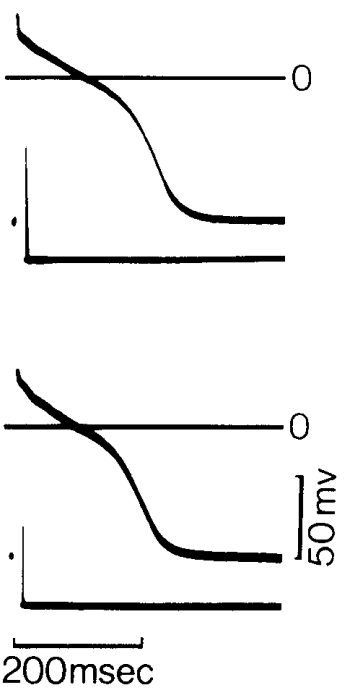

Fig.5. Actual recordings of action potentials obtained from a subendocardial Purkinje fiber of normal preparation (the upper panels) and of infarcted preparation (the lower panels) 15, 30, and $60 \mathrm{~min}$ after exposure to the hypoxic solution. The format in each panel is the same as in Fig. 3. Both in normal and infarcted preparations, all parameters of action potential characteristics improved progressively with the time of superfusion. Calibrations: transmembrane potential-the right vertical bar shows $50 \mathrm{mV}$; Vmax-the left vertical bar shows $200 \mathrm{~V} / \mathrm{sec}$; time marks-the lower horizontal bar shows $200 \mathrm{msec}$.

after exposure to the hypoxic solution, action potentials of the subepicardial cells showed marked changes in their amplitudes and configurations, which were characterized by depolarization and by a progressive shortening of the action potential duration. In 3 out of 5 epicardial preparation, all the cells became electrically quiescent within $20-30 \mathrm{~min}$, even by an increase in the stimulating voltage or by moving the stimulating electrode to different positions (Fig. 3). In the remaining 2 epicardial preparations, all the cells continued to respond to electrical stimulation for more than $70 \mathrm{~min}$ of exposure to the hypoxic solution. However, in these preparations, the threshold voltages to evoke action potentials were markedly elevated from $1.0-1.5 \mathrm{~V}$ during the initial $10 \mathrm{~min}$ in the hypoxic solution to $7.0-9.0 \mathrm{~V}$ during the following $30 \mathrm{~min}$. At the end of 70 min under the hypoxic condition, the resting membrane potential was significantly lower than that under the well-oxygenated condition, and the duration of action potentials was also markedly shortened. It should be noticed that the resting membrane potential recorded at the initial stage of hypoxia $(10-20$ min in the hypoxic solution) was significantly lower than that observed at the end of the hypoxic period $(60-70 \mathrm{~min})$.

In contrast with the subepicardial cells, the subendocardial Purkinje fibers and the ordinary myocardial cells in all endocardial preparations responded to electrical stimulation for more than $70 \mathrm{~min}$ in the hypoxic solution (Fig. 4). As observed in the preparations under the welloxygenated condition, spontaneously occurring action potentials were recorded immediately after immersion in the hypoxic solution, but disappeared within 5-10 min. The mean value for the resting membrane potentials of the subendocardial Purkinje fibers measured in the initial 10-20 min under the hypoxic condition was $-74.0 \pm 6.0 \mathrm{mV}$, which was significantly lower than that of the controls. The action potential duration of the subendocardial Purkinje fibers shortened as compared with that of the controls. Although Vmax recorded in the initial stage of hypoxia was slightly higher than that of the controls, the action potential duration was significantly shortened (Table III). Each parameter of the action potentials increased gradually after exposure to the hypoxic solution (Fig. 5, upper panels, and Table III). 


$$
\begin{array}{ll}
\mathrm{K}^{+} 4.0 \quad \mathrm{~K}^{+} 7.0 &
\end{array}
$$

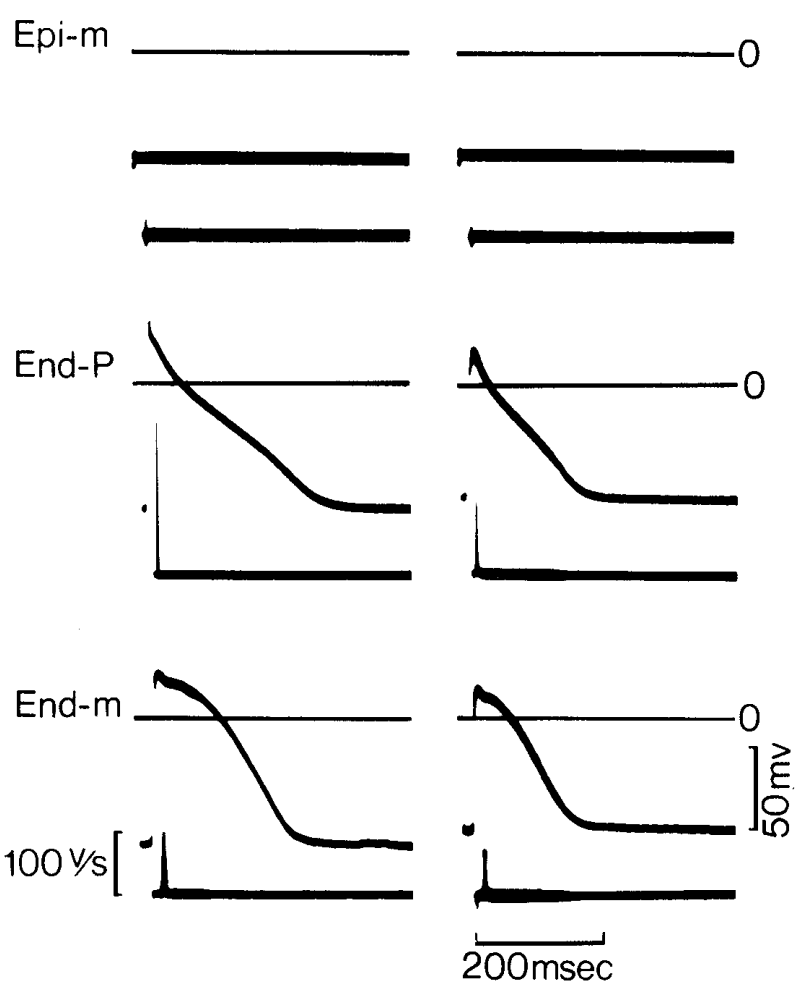

Fig.6. Effects of hypoxia and hyperkalemia (7 $\mathrm{mM}$ ) on a subepicardial cell, a subendocardial Purkinje fiber and an ordinary myocardial cell in infarcted preparation. The format in each panel is the same as in Fig. 3. The left panels are recordings taken under superfusion with the hypoxic solution containing $4 \mathrm{mM} \mathrm{K}^{+}$; the right panels are recordings taken under the hypoxic solution containing $7 \mathrm{mM} \mathrm{K}^{+}$. Calibrations: transmembrane potential- the right vertical bar shows $50 \mathrm{mV}$; Vmax-the left vertical bar shows $100 \mathrm{~V} / \mathrm{sec}$; time marks - the lower horizontal bar shows $200 \mathrm{msec}$ (see text for details).

The mean values for the resting membrane potentials, amplitudes and durations of the action potentials of the subendocardial ordinary myocardial cells recorded in the initial stage of hypoxia were significantly lower than those of the controls. Both resting membrane potentials and action potential amplitudes of the subendocardial ordinary myocardial cells gradually increased with the time of exposure to the hypoxic solution, but the action potential duration and Vmax were not significantly affected. However, the mean values for the resting membrane potentials, and amplitudes and durations of the action potentials were significantly less than those of the controls.

Infarcted Preparations: Immediately after transferring the preparations into the hypoxic solution, the subepicardial cells in all 5 infarcted preparations showed no spontaneous electrical activity, but responded to electrical stimulation and elicited action potentials. Within 5-10 min in the hypoxic solution these cells responded to electrical stimulation in a $2: 1$ or 3:1 manner, and then ceased to respond. There was no statistical difference between the mean value of the resting membrane potentials of normal preparations and that of infarcted preparations at $60 \mathrm{~min}$ in the hypoxic solution, but when compared with that of the controls, the subepicardial cells of infarcted preparations were significantly depolarized.

The subendocardial Purkinje fibers and the ordinary myocardial cells of infarcted preparations both preserved electrical activities for more than $70 \mathrm{~min}$ in the hypoxic solution. Immediately after exposure to this solution, there was no spontaneous electrical activity such as observed in normal preparations, but these cells responded to electrical stimulation and elicited action potentials. The values of each parameter of the action potential, especially those of the action potential duration, gradually increased after exposure to the hypoxic solution. Actual records of action potentials obtained from a subendocardial Purkinje fiber of infarcted preparation after exposure to the hypoxic solution are shown in Fig. 5 (lower panels). The mean values of the action potential durations and Vmax of the subendocardial Purkinje fibers of infarcted preparations at $60 \mathrm{~min}$ in the hypoxic solution were significantly lower than those of normal preparations at $60 \mathrm{~min}$ in the hypoxic solution, while the mean values of the resting membrane potentials and action potential amplitudes were not (Table III). The mean value of the action potential durations of the subendocardial Purkinje fibers of infarcted preparations was significantly lower than that of the controls, but those of the resting membrane potentials, action potential amplitudes and Vmax were not significantly different from those of the controls (Table III).

The mean values of the resting membrane potentials, action potential amplitudes and durations of the subendocardial ordinary myocardial cells of infarcted preparations both at the initial stage and at $60 \mathrm{~min}$ in the hypoxic solution were significantly different from the controls (Table III). In the initial stage of hypoxia, there was no difference in action potential characteristics 

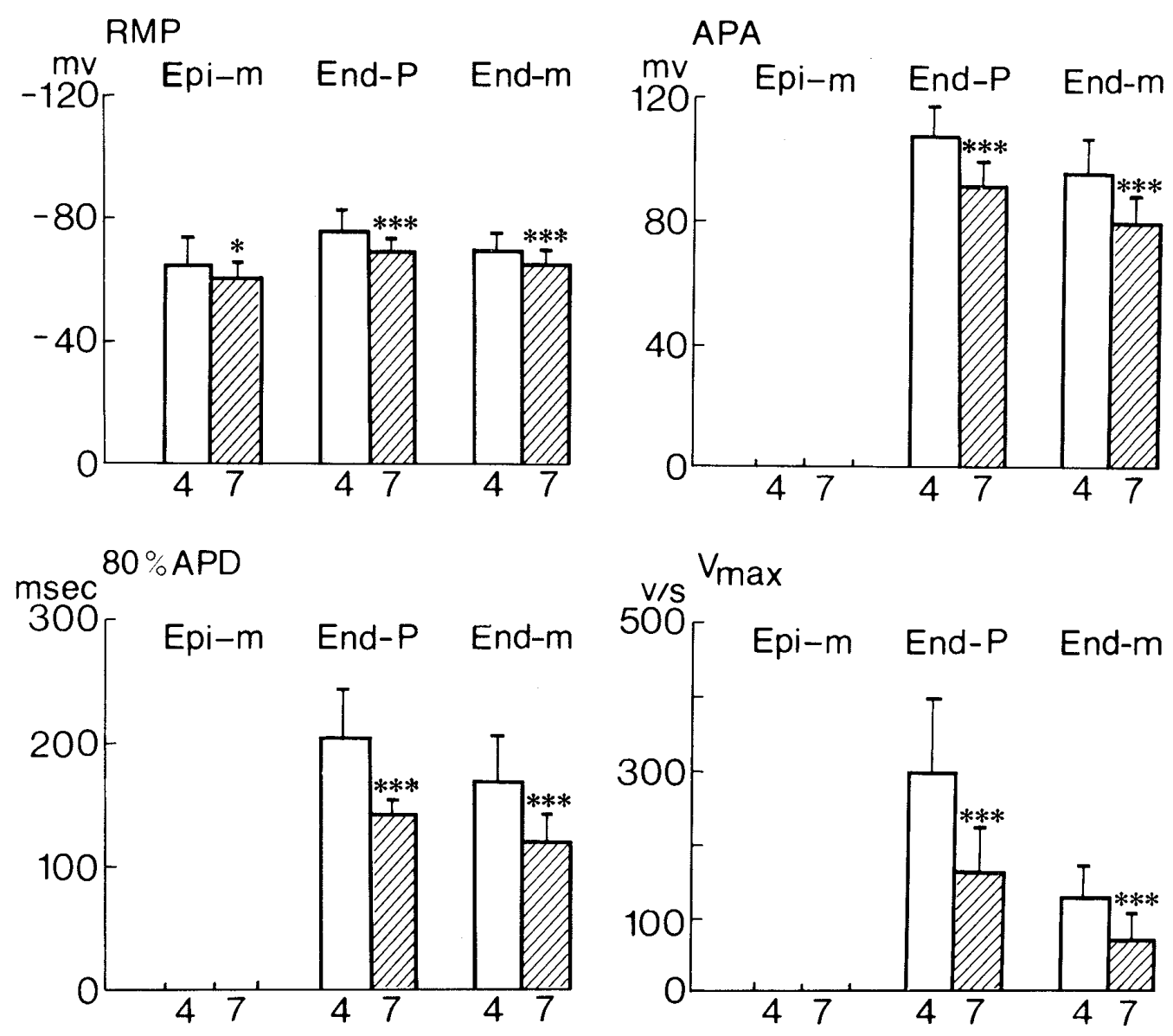

Fig.7. Effects of extracellular $\mathrm{K}^{+}$concentration $(4$ and $7 \mathrm{mM}$ ) on the resting membrane potentials(RMP), action potential amplitudes(APA), action potential durations at $80 \%$ repolarization ( $80 \%$ APD), and Vmax of the subepicardial cells, the subendocardial Purkinje fibers, and the ordinary myocardial cells in infarcted preparations. In each panel, the left columns show the values of the subepicardial cells, the middle columns the subendocardial Purkinje fibers and the right columns the subendocardial ordinary myocardial cells. In each column, the white bar shows the values in the hypoxic solution containing $4 \mathrm{mM} \mathrm{K}^{+}$, the hatched bar shows those in the hypoxic solution containing $7 \mathrm{mM} \mathrm{K}$. Each bar shows the mean $\pm \mathrm{SD}$. The significance of the difference between the values in the hypoxic solution containing $4 \mathrm{mM} \mathrm{K}^{+}$and those in the hypoxic solution containing 7 $\mathrm{mM} \mathrm{K}^{+}$is denoted by $*=\mathrm{p}<0.05$ and $* * *=\mathrm{p}<0.001$.

between infarcted and normal preparations. Action potential durations were markedly longer at $60 \mathrm{~min}$ in the hypoxic solution than those at the initial stage. The mean values of the resting membrane potentials, and amplitudes and durations (50\% APD only) of action potentials at 60 $\min$ in the hypoxic solution were significantly lower than those of normal preparations (Table III).

Effects of an Increase in External $K^{+}$-concentration on the Infarcted Myocardium under a Hypoxic Condition

The subepicardial cells of infarcted preparations ceased to respond to electrical stimulation within $5-10 \mathrm{~min}$ after exposure to the hypoxic solution containing $7 \mathrm{mM} \mathrm{K}^{+}$, while the subendocardial Purkinje fibers and the ordinary myocardial cells continued to elicit action potentials by electrical stimulation for more than $70 \mathrm{~min}$ in the hypoxic and hyperkalemic solution. An increase in external $\mathrm{K}^{+}$-concentration from 4 to 7 $\mathrm{mM}$ produced marked changes in the resting membrane potentials and action potential amplitudes of neither the subendocardial Purkinje fibers nor the ordinary myocardial cells. However, the values for the action potential durations and Vmax were markedly reduced by increasing the external $\mathrm{K}^{+}$-concentration to $7 \mathrm{mM}$ (Figs. 6 and 7). In the subendocardial Purkinje fibers of 
TABLE IV EFFECTS OF HYPOXIA AND HYPERKALEMIA (7 mM) ON ACTION POTENTIAL CHARACTERISTICS OF ISCHEMIC AND NORMAL CARDIAC CELLS

\begin{tabular}{cccccccc}
\hline Cells & Preparation & $n$ & $\begin{array}{c}\text { RMP } \\
(\mathrm{mV})\end{array}$ & $\begin{array}{c}A P A \\
(\mathrm{mV})\end{array}$ & $\begin{array}{c}50 \% \text { APD } \\
(\mathrm{msec})\end{array}$ & $\begin{array}{c}80 \% \text { APD } \\
(\mathrm{msec})\end{array}$ & $\begin{array}{c}V \max \\
(\mathrm{V} / \mathrm{sec})\end{array}$ \\
\hline \multirow{2}{*}{ Epi-m } & $N$ & 44 & $59.0 \pm 4.2$ & $N D$ & $N D$ & $N D$ & $N D$ \\
& $I$ & 45 & $61.3 \pm 4.8$ & $N D$ & $N D$ & $N D$ & $N D$ \\
End-P & $N$ & 26 & $67.8 \pm 5.1$ & $93.7 \pm 5.8$ & $120.3 \pm 21.4$ & $160.6 \pm 27.4$ & $227.2 \pm 76.4$ \\
& $I$ & 41 & $69.4 \pm 4.5$ & $92.6 \pm 6.9$ & $101.4 \pm 18.5$ & $143.1 \pm 15.1 * *$ & $169.0 \pm 52.1 * * *$ \\
\multirow{2}{*}{ End-m } & $N$ & 25 & $65.2 \pm 3.7$ & $86.6 \pm 8.7$ & $110.8 \pm 31.2$ & $131.8 \pm 34.0$ & $98.1 \pm 37.6$ \\
& $I$ & 31 & $65.5 \pm 4.4$ & $80.3 \pm 8.9 *$ & $93.6 \pm 19.2 *$ & $121.5 \pm 21.7$ & $72.5 \pm 37.9 *$ \\
\hline
\end{tabular}

Each value respresents the mean $\pm S D$ of cardiac action potential characteristics obtained from 5 infarcted(I) and 3 normal $(N)$ preprarations 60-70 min after superfusion with the hypoxic and hyperkalemic $\left(7 \mathrm{mM} \mathrm{K} \mathrm{K}^{+}\right.$) solution. $*=p<0.05, * *=p<0.005, * * *=P<0.001$ : significance of the difference between the infarcted preparations and normal preparations under the hypoxic and hyperkalemic conditions. $N D=$ No data due to a lack of response to electrical stimulation.

infarcted preparations, the action potential duration was shortened and the Vmax was reduced as compared with those in normal preparations under the hypoxic and hyperkalemic $(7 \mathrm{mM})$ conditions. In the subendocardial ordinary myocardial cells of infarcted preparations, the action potential amplitude and Vmax were reduced and the action potential duration was shortened as compared with those of normal preparations under similar conditions. However, the mean value of the resting membrane potentials was not different between normal and infarcted preparations (Table IV). A further increase in external $\mathrm{K}^{+}$-concentration to $15 \mathrm{mM}$ resulted in a marked depolarization in all myocardial cells of the subepicardium and the subendocardium, and these cells did not respond to electrical stimulation. The mean values of the resting membrane potentials of the subepicardial cells and the subendocardial cells were $-50.8 \pm 4.6 \mathrm{mV}$ $(\mathrm{n}=20)$ and $-51.3 \pm 5.3 \mathrm{mV}(\mathrm{n}=20)$, respectively. Even with an addition of norepinephrine $\left(5 \times 10^{-6} \mathrm{M}\right)$ to the hypoxic solution containing $15 \mathrm{mM} \mathrm{K}^{+}$, slow response could not be induced in any preparation.

\section{DISCUSSION}

\section{Infarcted Myocardium in the Hypoxic Solution}

The present experiments have shown that the subepicardial cells obtained one hour after the coronary artery ligation lost their electrical activ. ities within an initial 5-10 min period of exposure to the hypoxic solution, while the subendo- cardial Purkinje fibers and the ordinary myocardial cells continued to respond to electrical stimulation and initiate action potentials for more than $70 \mathrm{~min}$ in the hypoxic solution. These differences of the electrophysiological properties in response to hypoxia were also observed in normal preparations. The present results confirm previous observations that the subendocardial Purkinje fibers were more resistant to anoxia or ischemia than the other myocardial cells, $, 8,31-33$ and indicate that the subepicardial cells are more sensitive to hypoxia than the subendocardial ordinary myocardial cells or the Purkinje fibers. That is to say, the lack of oxygen is a major damaging factor in the subepicardium. These electrophysiological properties of the subepicardial cells may be responsible for the marked subepicardial conduction delay of the ischemic regions in the early phase of acute coronary occlusion., 10

The ischemic myocardial cells under the hypoxic condition were characterized by a significant depolarization and a reduction of the action potential amplitudes of the subendocardial ordinary myocardial cells, by a shortening of the action potential duration and by a reduction of Vmax of the subendocardial Purkinje fibers. However, the subepicardial cells were not different in these respects from normal preparations under similar conditions. These findings indicate that the membrane characteristics of the ischemic myocardium one hour after coronary occlusion had already altered, even if the subendocardial cells were adequately nourished by a diffusion 
from the ventricular cavity blood.

Most previous microelectrode studies of the myocardium have been conventionally performed more than $60 \mathrm{~min}$ after superfusion with a welloxygenated solution. However, since various electrophysiological changes might occur within an initial 60-min superfusion period, we examined the time course of changes in electrophysiological properties of ischemic myocardium under superfusion with the hypoxic solution. The present results showed that the values of electrophysiological properties of both the normal and infarcted subendocardial cells were partially reversed by prolonged superfusion even under the hypoxic condition. These time courses of changes in the values of electrophysiological properties under the hypoxic condition were unexpected, since it is known that hypoxia is a depressant factor of the electrophysiological activities of the cardiac cells. ${ }^{34}$ At this time, we do not know the precise mechanisms of these changes obtained under the prolonged superfusion with the hypoxic solution. Changes in the extracellular environment or in cellular metabolism, mechanical trauma and others could be factors. Previous investigators indicated that the subendocardial Purkinje fibers in the infarcted region were especially sensitive to mechanical trauma, ${ }^{7}$ and that there was little electrophysiological difference between the ischemic and the normal zone 10-15 min after excision in the canine heart subjected to $20-30$ min coronary occlusion? In the present experiment there was also no significant difference between most electrophysiological properties in normal preparations and those in infarcted preparations in the initial superfusion period with the hypoxic solution. Thus, our data may indicate that mechanical trauma is not a main factor in these changes. Furthermore, it has been reported that a rapid recovery of the membrane potential in cat papillary muscles at $27-28^{\circ} \mathrm{C}$ occurred after hypothemia for 2 hours at $4-$ $6^{\circ} \mathrm{C}^{35}$ Therefore, the influence of temperature on the electrophysiological changes may be negligible in the present study. Finally, it is most likely that there are differences in the extracellular environment between in vivo and in vitro studies, in both normal and infarcted preparations, may be responsible for these changes. It has been shown that in infarcted region the extracellular $\mathrm{K}^{+}$or metabolic substances accumulate around the surface membrane of the ischemic myocardial cells.22,23,25-27 This time course of changes in the electrophysiological properties of the subendocardial cells under superfusion with the hypoxic solution could be explained by the idea that the extracellular $\mathrm{K}^{+}$or metabolic substances may be washed out after this period of superfusion, even under the hypoxic condition. It should be noticed that the value of the action potential duration of the subendocardial ordinary myocardial cells in infarcted preparations was partially reversed without remarkable changes in the other electrophysiological parameters, while that of normal preparations was not reversed significantly. Under superfusion with the hypoxic solution containing high potassium $(7 \mathrm{mM})$ the values of electrophysiological properties of the subendocardial cells in infarcted preparations were deteriorated (Table IV and Fig. 6). Thus, it is suggested that a marked rise in extracellular $\mathrm{K}^{+}$following acute coronary occlusion probably produces depressant effects on the electrophysiological activities of the ischemic myocardial cells. However, the present results may not be completely applicable to the electrophysiological activities of the subendocardial Purkinje fibers in the ischemic region, since the subendocardial Purkinje fibers are flushed by ventricular cavity blood.

\section{Infarcted Myocardium in the Well-oxygenated Solution}

Previous investigators reported that the subendocardial Purkinje fibers and the ordinary myocardial cells in the infarcted region showed a variety of electrical activities when transferred into a well-oxygenated solution: some cells exhibited spontaneous diastolic depolarizations or rapid repetitive generation of spontaneously occurring action potentials, and in other cells the time course of repolarization was markedly prolonged 5-8 Similar results were obtained in the present experiments where infarcted preparations were superfused with the well-oxygenated solution. In the endocardial preparation, action potentials with slow diastolic depolarization were recorded (Fig. 2). They were blocked by verapamil. Results indicate that slow inward currents are mainly responsible for the initiation of these action potentials. It has been suggested that this type of automaticity may participate in the generation of certain types of arrhythmias ${ }^{36}$ This might occur in situ only if one assumes that the several subendocardial cell layers are adequately oxygenated by simple diffusion of oxygen from ventricular cavity blood, by retrograde perfusion through ventricular sinusoidal chan- 
nels ${ }^{37}$ and/or by collateral blood flow even after extensive myocardial infarction. This situation is similar to experimental conditions in vitro used by previous investigators $5-8$ However, it should be noted that under the hypoxic condition in the present experiment, there was no spontaneous activity, even though the subendocardial Purkinje fibers and the ordinary myocardial cells could initiate action potentials in response to electrical stimulation. It is most likely that the observed abnormalities of the action potentials under the well-oxygenated condition, including the prolonged repolarization phase, might be due to alterations of the cell membrane of the ischemic myocardial cells resulting from sudden reoxygenation, but they do not reflect the true changes of electrophysiological ptoperties of the ischemic myocardial cells in situ. In fact, the changes in permeability of the ischemic myocardial cell membrane to a certain ion, such as $\mathrm{Ca}^{+}$, after reoxygenation have been reported 38,39 However, the precise mechanisms underlying the initiation of the spontaneous activity and the prolongation of the action potential duration are not certain. A possible explanation is that $\mathrm{Ca}^{++}$inward current may be responsible for the spontaneous activity and the prolongation of the action potential duration. This idea comes from the observation that spontaneously occurring action potentials with apparent phase 4 depolarization diminished after the application of verapamil, which is known as a potent organic $\mathrm{Ca}^{++}$antagonist and a slow-channel blocker40,41 Furthermore, the prolonged repolarization phase was also shortened by this agent (Yoshikawa and Nishi, unpublished observation).

\section{Clinical Implication}

Our study does not provide insight into the cause of ventricular arrhythmias occurring in the acute stage of coronary occlusion. Nevertheless, it provides some information on the electrical activity of the ischemic myocardial cell in situ. Although previous investigators reported that the rise in extracellular $\mathrm{K}^{+}$was a major factor in ischemia-induced ventricular arrhythmias, ${ }^{18-20}$, 42,43 our results can explain only the depolarization, the shortening of the action potential duration, and the reduction of $V \max$ as being the effects of an increase in extracellular $\mathrm{K}^{+}$per se (Table IV). It has been proposed that the slow response induced by elevated extracellular $\mathrm{K}^{+}$and catecholamine release may play an important role in initiating ventricular arrhythmias follow- ing acute coronary occlusion. ${ }^{12,14,44,45}$ However, in the hypoxic solution containing a high concentration of $\mathrm{K}^{+}(15 \mathrm{mM})$, the ischemic myocardial cells became depolarized and electrically quiescent, even when exposed to large voltage stimulation to the preparations, and slow response was not induced in the hypoxic solution containing $15 \mathrm{mM} \mathrm{K}$ and norepinephrine $\left(5 \times 10^{-6} \mathrm{M}\right)$. Schneider and Sperelakis $^{46}$ reported that slow responses were blocked by metabolic poisons, hypoxia or ischemia. Therefore, it is most reasonable to conclude that slow responses may not be induced by catecholamine release at the severe or the prolonged ischemic regions in situ, possibly with severe hypoxia and hyperkalemia. Finally, our results support the idea that under regional hypoxia and hyperkalemia resulting from acute coronary occlusion, heterogeneous changes in electrical activity occur between the subepicardium and the subendocardium of the ischemic regions.

\section{Acknowledgement}

The authors would like to acknowledge the valuable criticisms and suggestions by Dr. Masayuki Ando, First Department of Internal Medicine, Kumamoto University Medical School, in preparing the manuscript.

\section{REFERENCES}

1. SCHERLAG BJ, HALFANT RH, HAFT JI, DAMOTO AN: Electrophysiology underlying ventricular arrhythmias due to coronary ligation. $A m$ J Physiol 219: 1665, 1970

2. 'BOINEAU JP, COX JL: Slow ventricular activation in acute myocardial infarction: A source of re-entrant premature ventricular contractions. Circulation 48: 702, 1973

3. WALDO AL, KAISER GA: A study of ventricular arrhythmias associated with acute myocardial infarction in the canine heart. Circulation 47: 1222,1973

4. KAPLINSKY E, OGAWA S, BALKE CW, DREIFUS LS: Two period of early ventricular arrhythmia in the canine acute myocardial infarction model. Circulation 60: 397, 1979

5. FRIEDMAN PL, STEWART JR, FENOGLIO JJ Jr, WIT AL: Survival of subendocardial Purkinje fibers after extensive myocardial infarction in dogs: In vitro and in vivo correlations. Circ Res 33: 597,1973

6. FRIEDMAN PL, STEWART JR, WIT AL: Spontaneous and induced cardiac arrhythmias in subendocardial Purkinje fibers surviving extensive myocardial infarction in dogs. Circ Res 33: 612, 1973

7. LAZZARA R, EL-SHERIF N, SCHERLAG BJ: Electrophysiological properties of canine Purkinje cells in one-day-old myocardial infarction. Circ Res 33: 722, 1973 
8. LAZZARA R, EL-SHERIF N, SCHERLAG BJ: Early and late effects of coronary artery occlusion on canine Purkinje fibers. Circ Res 35: 391, 1974

9. DURRER D, VAN DAM RT, FREUD GE, JANSE MJ: Re-entry and ventricular arrhythmias in local ischemia and infarction of the intact dog heart. Proc K Ned Akad Wt [Biol Med] 74: 321, 1971

10. SCHERLAG BJ, EL-SHERIF N, HOPE R, LAZZARA R: Characterization and localization of ventricular arrhythmias resulting from myocardial ischemia and infarction. Circ Res 35: 372, 1974

11. JANE MJ, VAN CAPELLE FJL, MORSINK H, KLEBER AG, WILMS-SHOPMAN F, CARDINAL R, D'ALNONCOURT CN, DURRER D: Flow of "injury" current and patterns of excitation during early ventricular arrhythmias in acute regional myocardial ischemia in isolated porcine and canine hearts: Evidence for two different arrhy thmogenic mechanisms. Circ Res 47: 151, 1980

12. KUPERSMITH J, COHEN R: Differing electrophysiologic effects of slow response inhibiting agents manganese and verapamil on ischemic, infarcted and normal tissue in situ. J Pharmacol Exp Ther 215: 394, 1980

13. DOWNAR E, JANSE MJ, DURRER D: The effect of acute coronary artery occlusion on subepicardial transmembrane potentials in the intact porcine heart. Circulation 56: 217, 1977

14. RUSSELL DC, SMITH HJ, OLIVER MF: Transmembrane potential changes and ventricular fibrillation during repetitive myocardial ischemia in the dog. Br Heart J 42: 88, 1979

15. MORENA H, JANSE MJ, FIOLET JWT, KRIEGER WJG, CRIJNS H, DURRER D: Comparison of the effects of regional ischemia, hypoxia, hyperkalemia, and acidosis on intracellular and extracellular potentials and metabolism in the isolated porcine heart. Circ Res 46: 634, 1980

16. FRIEDMAN PL, FENOGLIO JJ Jr, WIT AL: Time course for reversal of electrophysiological and ultrastructural abnormalities in subendocardial Purkinje fibers surviving extensive myocardial infarction in dogs. Circ Res 36: 127, 1975

17. WINBURY MM, HOWE BB, WEISS HR: Effect of nitroglycerin and dipyridamole on epicardial and endocardial oxygen tension: Further evidence for redistribution of myocardial blood flow. J Pharmacol Exp Ther 176: 184, 1971

18. DOWNAR E, JANSE MJ, DURRER D: The effect of "ischemic" blood on transmembrane potentials of normal porcine ventricular myocardium. Circulation 55: 455, 1977

19. HARRIS AS, BISTENI A, RUSSELL RA, BRIGHAM JC, FIRESTONE JE: Excitatory factors in ventricular tachycardia resulting from myocardial ischemia: Potassium a major excitant. Science 119: 200, 1954

20. CASE RB, NASSER MG, CRAMPTON RS: Biochemical aspects of early myocardial ischemia. $\mathrm{Am}$ J Cardiol 24: 766, 1969

21. THOMAS M, SHULMAN G, OPIE L: Arteriovenous potassium changes and ventricular arrhythmias after coronary occlusion. Cardiovasc Res 4: 327,1970

22. HILL JL, GETTES LS: Effect of acute coronary artery occlusion on local my.ocardial extracellular $\mathrm{K}^{+}$activity in swine. Circulation 61: 768, 1980

23. HIRCHE HJ, FRANZ CHR, BÖS L, BISSIG R, LANG R, SCHRAMM M: Myocardial extracellular $\mathrm{K}^{+}$and $\mathrm{H}^{+}$increase and noradrenaline release as possible cause of early arrhythmias following acute coronary artery occlusion in pigs. $J \mathrm{Mol}$ Cell Cardiol 12: 579,1980

24. OPIE LH: Effects of regional ischemia on metabolism of glucose and fatty acids: Relative rates of aerobic and anaerobic energy production during myocardial infarction and comparison with effects of anoxia. Circ Res 38 (Suppl I): 52, 1976

25. OPIE LH, OWEN P, THOMAS M, SAMSON R: Coronary sinus lactate measurements in assessment of myocardial ischemia: Comparison with changes in lactate/pyruvate and beta-hydroxybutyrate/ actetoacetate ratios and with release of hydrogen, phosphate and potassium ions from the heart. $\mathrm{Am}$ J Cardiol 32: 295, 1973

26. VETTER NJ, STRANGE RC, ADAMS W, OLIVER MF: Initial metabolic and hormonal response to acute myocardial infarction. Lancet 1: 284, 1974

27. SOBEL BE, CORR PB, ROBINSON AK, GOLDSTEIN RA: Accumulation of lysophosphoglycerides with arrhythmogenic properties in ischemic myocardium. $J$ Clin Invest 62: 546, 1978

28. HARRIS AS: Delayed development of ventricular ectopic rhy thms following experimental coronary occlusion. Circulation 1: 1318, 1950

29. SNEDECOR GW, COCHRAN WG: Statistical Methods. Iowa State University Press, Iowa, 1980, p 83

30. HOFFMAN BF, CRANEFIELD PF: Electrophysiology of the Heart. McGraw-Hill, New York, 1960, p $75 ;$ p 175

31. GILMOUR RF Jr, ZIPES DP: Different electrophysiological responses of canine endocardium and epicardium to combined hyperkalemia, hypoxia, and acidosis. Circ Res 46: 814, 1980

32. BAGDONAS AA, STUCKEY JH, PIERA J, AMER NS, HOFFMAN BF: Effects of ischemia and hypoxia on the specialized conducting system of the canine heart. Am Heart J 61: 206, 1961

33. FOZZARD HA: Validity of myocardial infarction models. Circulation 51, 52 (Supp1 III): 131, 1975

34. TRAUTWEIN W, GOTTSTEIN U, DUDEL J: Der Aktionsstrom der Myokardfaser im Sauerstoffmangel. Pflügers Arch 260: 40, 1954

35. PAGE E, STORM SR: Cat heart muscle in vitro (VIII): Active transport of sodium in papillary muscles. J Gen Physiol 48: 957, 1965

36. WIT AL, WIGGINS JR, CRANEFIELD PF: Some effects of electrical stimulation on impulse initiation in cardiac fibers: Its relevance for the determination of the mechanisms of clinical cardiac arrhythmias. In The Conduction System of the Heart, ed by WELLENS HJJ, LEE KI, JANSE MJ, H E Stenfert Kroese BV, Leiden, 1976, p 163

37. MYERS WW, HONIG CR: Amount and distribution of $\mathrm{Rb}^{86}$ transported into myocardium from ventricular lumen. Am J Physiol 211: 739, 1966

38. SHEN AC, JENNINGS RB: Myocardial calcium and magnesium in acute ischemic injury. $A m J$ Pathol 67: 417, 1972

39. JENNINGS RB, GANOTE CE: Structural changes 
in myocardium during acute ischemia. Circ Res 34, 35 (SuppI III): 156, 1974

40. KOHLHARDT M, BAUER B, KRAUSE $H$, FLECKENSTEIN A: Differentiation of the transmembrane $\mathrm{Na}$ and $\mathrm{Ca}$ channels in mammalian cardiac fibres by the use of specific inhibitors. Pflügers Arch 335: 309, 1972

41. SHIGENOBU K, SCHNEIDER JA, SPERELAKIS $\mathrm{N}$ : Verapamil blockade of slow $\mathrm{Na}^{+}$and $\mathrm{Ca}^{++}$ responses in myocardial cells. J Pharmacol Exp Ther 190: 280, 1974

42. CHERBAKOFF A, TOYAMA S, HAMILTON WF: Relation between coronary sinus plasma potassium and cardiac arrhy thmia. Circ Res 5: 517, 1957
43. HARRIS AS: Potassium and experimental coronary occlusion. Am Heart $J$ 71: 797, 1966

44. CRANEFIELD PF, WIT AL, HOFFMAN BF: Conduction of the cardiac impulse (III): Characteristics of very slow conduction. J Gen Physiol 59: 227,1972

45. OPIE LH, NATHAN D, LUBBE WF: Biochemical aspects of arrhy thmogenesis and ventricular fibrillation. Am J Cardiol 43: 131, 1979

46. SCHNEIDER JA, SPERELAKIS N: Slow $\mathrm{Ca}^{2+}$ and $\mathrm{Na}^{+}$responses induced by isoproterenol and methylxanthines in isolated perfused guinea pig hearts exposed to elevated $\mathrm{K}^{+}$. J Mol Cell Cardiol 7: 249, 1975 